\title{
Findings About Events or Interventions Original Result Unit
}

National Cancer Institute

\section{Source}

National Cancer Institute. Findings About Events or Interventions Original Result Unit. NCI

Thesaurus. Code C113365.

The unit of measure for the original findings about events or interventions result. 